University of Montana

ScholarWorks at University of Montana

$2-5-2014$

\title{
A Conceptual Framework for Clutch-Size Evolution in Songbirds
}

Thomas E. Martin

University of Montana - Missoula

Follow this and additional works at: https://scholarworks.umt.edu/wildbio_pubs

Part of the Animal Sciences Commons, and the Evolution Commons

Let us know how access to this document benefits you.

\section{Recommended Citation}

Martin, Thomas E., "A Conceptual Framework for Clutch-Size Evolution in Songbirds" (2014). Wildlife Biology Faculty Publications. 95.

https://scholarworks.umt.edu/wildbio_pubs/95

This Article is brought to you for free and open access by the Wildlife Biology at ScholarWorks at University of Montana. It has been accepted for inclusion in Wildlife Biology Faculty Publications by an authorized administrator of ScholarWorks at University of Montana. For more information, please contact scholarworks@mso.umt.edu. 


\title{
A Conceptual Framework for Clutch-Size Evolution in Songbirds
}

\author{
Thomas E. Martin* \\ US Geological Survey, Montana Cooperative Wildlife Research Unit, University of Montana, Missoula, Montana 59812 \\ Submitted May 26, 2013; Accepted October 30, 2013; Electronically published February 5, 2014 \\ Online enhancement: appendix. Dryad data: http://dx.doi.org/10.5061/dryad.8415f,
}

\begin{abstract}
AвSTRACт: Causes of evolved differences in clutch size among songbird species remain debated. I propose a new conceptual framework that integrates aspects of traditional life-history theory while including novel elements to explain evolution of clutch size among songbirds. I review evidence that selection by nest predation on length of time that offspring develop in the nest creates a gradient in offspring characteristics at nest leaving (fledging), including flight mobility, spatial dispersion, and self-feeding rate. I postulate that this gradient has consequences for offspring mortality rates and parental energy expenditure per offspring. These consequences then determine how reproductive effort is partitioned among offspring, while reproductive effort evolves from age-specific mortality effects. Using data from a long-term site in Arizona, as well as from the literature, I provide support for hypothesized relationships. Nestling development period consistently explains fledgling mortality, energy expenditure per offspring, and clutch size while accounting for reproductive effort (i.e., total energy expenditure) to thereby support the framework. Tests in this article are not definitive, but they document previously unrecognized relationships and address diverse traits (developmental strategies, parental care strategies, energy requirements per offspring, evolution of reproductive effort, clutch size) that justify further investigations of hypotheses proposed here.
\end{abstract}

Keywords: nest predation, developmental strategy, parental care, reproductive effort, fledgling mortality, age-specific mortality.

\section{Introduction}

Clutch size is a pivotal life-history trait because it reflects both fecundity and reproductive effort (Lack 1948; Williams 1966; Martin 1987; Roff 2002). Hypotheses for the evolutionary basis of clutch-size variation among species have been widely espoused (Lack 1948; Williams 1966; Godfray et al. 1991; Roff 2002; Jetz et al. 2008). Yet general support for any individual hypothesis remains weak, and mechanistic causes are widely debated.

Four sets of hypotheses have received the most attention: (1) Lack's food-limitation hypothesis suggests that

\footnotetext{
* E-mail: tom.martin@umontana.edu.
}

Am. Nat. 2014. Vol. 183, pp. 313-324. Copyright is not claimed for this article. DOI: $10.1086 / 674966$ parents raise the maximum number of young allowed by food resources (Lack 1948; Godfray et al. 1991); (2) nestpredation hypotheses posit that clutch size decreases with increasing predation risk because of reduced parental feeding rates of offspring (Skutch 1949) or reduced allocation of energy for the current attempt to allow repeat breeding attempts (Slagsvold 1984; Martin 1995); (3) Ashmole's seasonality hypothesis suggests that increasing seasonality causes greater overwinter mortality from resource scarcity at higher latitudes and provides more per capita resources for breeding that allow larger clutch sizes (Ashmole 1961; Jetz et al. 2008); and (4) the age-specific mortality hypothesis suggests that extrinsic mortality exerts selection on reproductive effort to determine clutch size (Williams 1966; Law 1979; Michod 1979; Charlesworth 1994; Martin 2002, 2004). These hypotheses are not mutually exclusive, and individually they have had difficulty explaining the full range of clutch-size variation among songbirds. For example, Lack's (1948) food-limitation hypothesis confuses proximate mechanisms with evolution and does not explain large differences among coexisting species foraging on similar food and at similar sites (Martin 1995, 2004; Roff 2002). Nest predation does not differ consistently with latitude and cannot explain major differences among latitudes (Martin et al. 2000). Ashmole's (1961) seasonality hypothesis does not explain clutch-size variation among species coexisting within a site. Age-specific mortality has considerable support in other taxa (Law 1979; Michod 1979; Crowl and Covich 1990; Reznick et al. 1990; Roff 2002) but has been dismissed for birds (e.g., Ricklefs 2010). Moreover, the age-specific mortality hypotheses focus on evolution of reproductive effort rather than on how effort is partitioned among young to determine clutch size. Thus, the mechanistic basis of evolved clutch-size variation among species remains unclear.

Here I propose a conceptual framework that integrates aspects of some prior hypotheses while also including novel elements to potentially explain evolution of clutch size among songbird species (fig. 1). In brief, I will argue 
that nest predation exerts selection on nestling development time to create a gradient in characteristics of young at fledging (i.e., when they leave the nest). The variation in fledgling characteristics affects fledgling mortality rates and per-offspring parental energy expenditure to influence clutch size. These effects are argued to interact with evolved total reproductive effort, which results from adult mortality and repeat breeding, as suggested by traditional life-history theory. This interaction can then explain why species with similar total reproductive effort have different clutch sizes. In the following, I detail the framework of nine hypotheses and provide supporting evidence for predictions underlying them. The evidence is sometimes indirect, but I provide the first documentation of previously unrecognized relationships and encourage further work to test the framework posited here.

\section{Methods}

I measured clutch size, duration of the nestling period (or age at fledging), body mass, and length of the wing on the day of fledging for songbird species at sites in Arizona where nesting biology has been studied for 27 years using methods described in Martin et al. $(2006,2011)$ and Cheng and Martin (2012), respectively. These traits were measured for 17 species of songbirds that are representatives of diverse clades distributed across Passeriformes. These birds were studied on 22 high-elevation $(\sim 2,350 \mathrm{~m}$ asl $)$ snow-melt drainages on the Mogollon Rim of northern Arizona (Martin 2007). Field data in this study are deposited in the Dryad Digital Repository: http://dx.doi.org /10.5061/dryad.8415f (Martin 2014).

I also obtained data on daily energy expenditure during the nestling feeding period (table A1; tables A1, A2 available online) and fledgling mortality over the first 21 days after leaving the nest (table A2) for as many north temperate passerine species as I could find in the literature. I included data found for one woodpecker because it is near passerines phylogenetically (Hackett et al 2008). Literature data on clutch size, duration of the nestling period, numbers of broods, body mass, and aerial foraging were taken from summaries in Martin (1995) and Martin and Clobert (1996).

Analyses were first made on raw data. Phylogenetically independent contrasts (PIC) were also calculated and analyzed to control for possible phylogenetic effects (Felsenstein 1985). I used the recent comprehensive phylogeny provided by Jetz et al. (2012). Phylogenetic trees for the species in the Arizona and literature data sets were obtained from www.birdtree.org (Jetz et al. 2012) using the Hackett et al. (2008) backbone and imported into Mesquite (Maddison and Maddison 2011) to construct a majority rule consensus tree based on 500 trees in each case.
The trees provided by Jetz et al. (2012) were time calibrated, such that branch lengths were included in analyses. Contrasts were calculated using the Phenotypic Diversity Analysis Programs (PDAP) module (Midford et al. 2002) and imported into SPSS (ver. 21) for linear regressions through the origin.

\section{Conceptual Framework for Clutch-Size Evolution}

\section{Natural Selection by Nest Predation on Fledgling Developmental Gradient}

Greater offspring predation risk can favor faster postnatal growth rates among species (Bosque and Bosque 1995; Remeš and Martin 2002; Martin et al. 2011). Of course, offspring predation is not the only influence on growth rates, as they can also differ among latitudes, potentially because of longevity trade-offs (Martin et al. 2011). Yet effect size of sites, which differed in latitude, is quite small compared with the dominant effects of nest predation (table 3 in Martin et al. 2011). It is well documented (Bosque and Bosque 1995; Martin 1995; Martin et al. 2011) that young at all latitudes leave the nest (i.e., fledge) after shorter nestling periods in songbird species with greater nest predation risk (fig. 1, hypothesis 1 ). What is less recognized is that, despite faster growth, the shorter nestling period of species with higher nest predation risk causes offspring to fledge at an earlier developmental state, as reflected by relatively smaller wings compared with adults (Cheng and Martin 2012). In short, these documented associations of nest predation risk with nestling development time create an unrecognized gradient in fledgling (offspring that have left the nest) characteristics across species. This gradient across species has gone unrecognized because fledgling studies have focused on individual species. Yet as I will describe, comparisons of these studies of individual species illustrate a clear gradient in developmental characteristics of fledglings (fig. 1, hypothesis 2: fledgling developmental gradient).

One potentially critical component of the developmental gradient is in relative wing size at fledging (i.e., Cheng and Martin 2012) and associated variation in fledgling mobility. Studies of individual species that use risky opencup nests have documented that young fledge with poorly developed wings and little ability to fly (e.g., Sullivan 1989; Kershner et al. 2004; Yackel-Adams et al. 2006; White and Faaborg 2008). In contrast, young in safe cavity nests fledge with better-developed wings and an ability to fly upon fledging (Royama 1966; Smith 1967; Brown 1978; With and Balda 1990). The better-developed wings of cavity-nesting species do not reflect nest height effects; cavitynesting Troglodytes aedon and Poecile gambeli fledge with wings that are $>80 \%$ of adult size, whereas canopy-nesting 


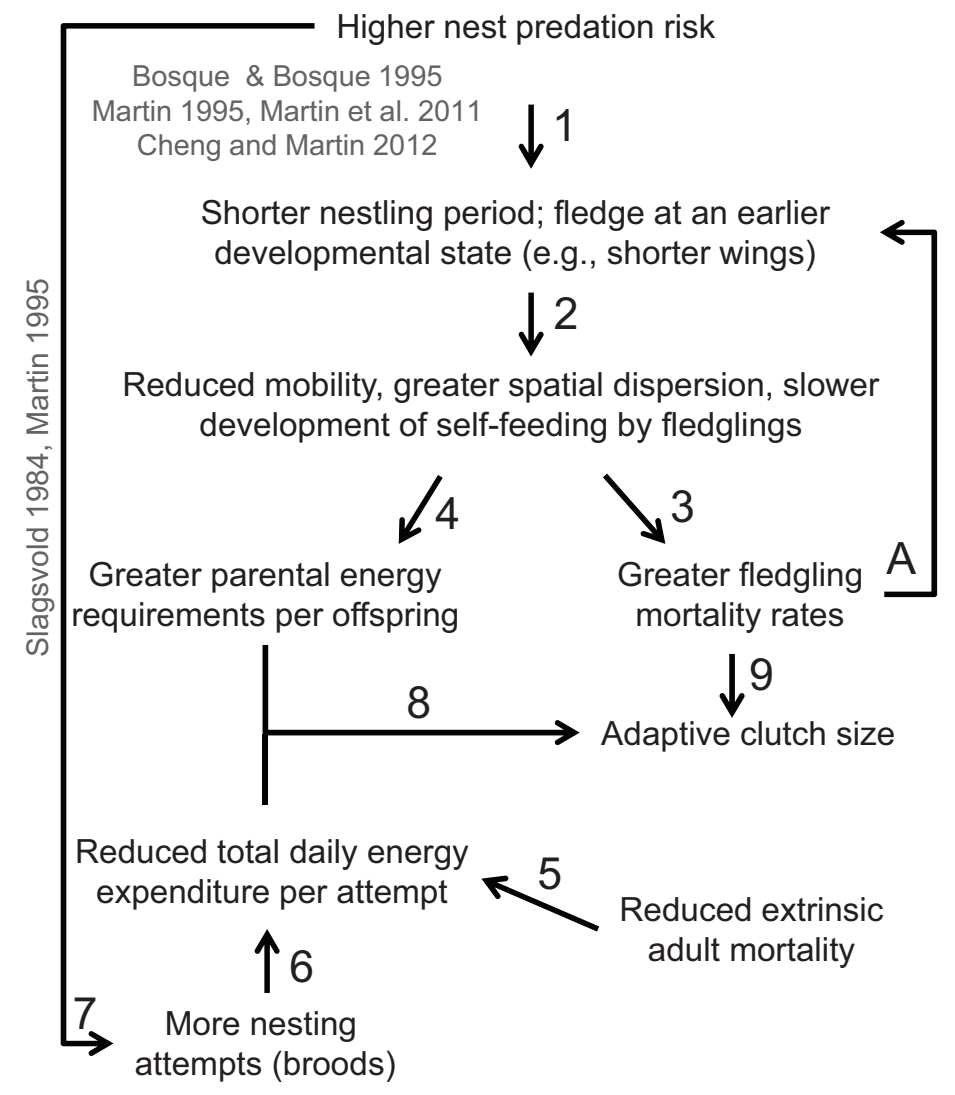

Figure 1: Conceptual framework for evolution of adaptive clutch size. Increased nest predation risk favors a shorter nestling period that causes young to leave the nest (i.e., fledge) at an earlier developmental stage, such as when wing sizes are shorter relative to adult wing size (1: predation selection on early fledging hypothesis). Age at fledging yields a gradient in fledgling characteristics, including reduced mobility, greater spatial dispersion, and slower rate of development of self-feeding for fledglings that fledge early (2: fledgling developmental gradient hypothesis). The fledgling characteristics resulting from an early age at fledging may increase fledgling mortality rates (3: fledgling mortality hypothesis) and the energy that parents must expend per offspring to feed dispersed offspring of low mobility and slow development of self-feeding (4: energy requirements per offspring hypothesis). Decreased reproductive effort, as reflected by total daily energy expenditure during a reproductive attempt, is expected to evolve in response to decreased adult mortality probability (5: adult mortality hypothesis) and increased numbers of nesting attempts (6: repeat breeding hypothesis) favored by greater nest predation risk (7: predation selection on within-season iteroparity hypothesis). Reproductive effort influences clutch size by being divided among young as a function of energy requirements per offspring as dictated by fledgling developmental characteristics (8: division of evolved reproductive effort hypothesis). Finally, an increase in fledgling mortality with reduced development at fledging may favor reduced clutch size to allow parents to provide more care to attempt to reduce mortality risk (9: parental adjustment of fledgling mortality risk hypothesis). Fledgling mortality should also feed back to influence the adaptive age at fledging (A: adaptive age at fledging hypothesis). Citations reflect already-documented relationships. Arrows reflect the hypothesized effect of one trait on another. Numbered hypotheses are either tested previously or tested in this article. Hypothesis A is not tested here.

Vireo gilvus, Turdus migratorius, and Piranga ludoviciana fledge with wings that are $<63 \%$ of adult size among species coexisting in Arizona (Cheng and Martin 2012; T. E. Martin, unpublished data). Moreover, relative wing size does not reflect foraging behavior and instead reflects natural selection by nest predation (Cheng and Martin 2012). Relative wing size at fledging varies on a continuous gradient among species (Cheng and Martin 2012) that reflects flight mobility (see above; T. E. Martin, personal observation) but has been unrecognized because of the focus on single-species studies.
Fledgling mobility may influence spatial dispersion of fledglings and covary with other developmental differences such as self-feeding. Studies of individual species suggest that the well-developed and flight-capable young that emerge after a long nestling period in safe nests, such as cavities, rapidly develop self-feeding and are quickly able to follow parents as a family group (Royama 1966; Smith 1967; Brown 1978; With and Balda 1990). In contrast, the short nestling periods of species from risky open nests are associated with less-developed young that have low mobility and take a long time to develop self-feeding (e.g., 
McLaughlin and Montgomerie 1985; Sullivan 1989; Anthonisen et al. 1997; Kershner et al. 2004; Yackel-Adams et al. 2006; White and Faaborg 2008). Moreover, these relatively low-mobility fledglings are often dispersed in space rather than grouped as a family (e.g., McLaughlin and Montgomerie 1985, 1989a; Anthonisen et al. 1997; Evans Ogden and Stutchbury 1997; White and Faaborg 2008).

Four single-species studies demonstrate this gradient in fledgling characteristics. Safe cavity-nesting Progne subis, which have a 28-day nestling period, are fully flight capable at fledging; fledglings group together and begin to feed themselves only 4 days after fledging (Brown 1978). Cavity-nesting Sialia mexicana, which have a 21-day nestling period, also move as a family group; they develop selffeeding at 4-6 days after fledging and are effectively independent from parental feedings after 2 weeks (With and Balda 1990). In contrast, open-nesting Hylocichla mustelina, which have a much higher nest predation risk, have a 12-day nestling period, and dispersed fledglings do not begin their first attempts at self-feeding until 15.3 days after fledging (Anders et al. 1997). Wilsonia citrina, which have a high predation risk and a 9-day nestling period, have fledglings that are also dispersed in space and do not become fully self-feeding and independent of parents until 28-30 days after fledging (Rush and Stutchbury 2008).

In summary, a proposed fledgling developmental gradient that includes relative wing size and associated mobility, spatial dispersion, and development of self-feeding seems apparent from individual studies (see above) and species in the Arizona system (Cheng and Martin 2012; T. E. Martin, personal observation). Further study of this gradient can advance understanding of the causes and consequences of differential developmental states across species. Potential consequences of this fledgling developmental gradient have not been considered in the context of clutch-size evolution. Yet the gradient may affect fledgling mortality (fig. 1, hypothesis 3) and energy requirements per offspring (fig. 1, hypothesis 4) to ultimately influence clutch size.

\section{Fledgling Mortality}

Parents are thought to be limited in the number of fledglings they can raise, and this in turn limits clutch size (Royama 1966; Edwards 1985; Kopachena and Falls 1993; Nesbitt Styrsky et al. 2005). Parental care limitation may cause starvation of fledglings (Magrath 1991; Suedkamp Wells et al. 2007). Yet fledgling mortality is highest in the first few days after fledging, and the vast majority of mortality is usually from predation that is unrelated to fledgling body condition (Anders et al. 1997; King et al. 2006; Yackel-Adams et al. 2006; Moore et al. 2010; Jackson et al. 2011; Streby and Andersen 2013). Parents attempt to counter predation risk by defending fledglings from predators (Moore et al. 2010) or leading offspring to safer sites (Raihani and Ridley 2007). These benefits may be increasingly constrained and yield increasing fledgling mortality along the fledgling developmental gradient (fig. 1, hypothesis 3: fledgling mortality); parental ability to spend time near young and reduce predation risk may decrease in species that fledge early and require parents to move among feeding sites and dispersed offspring with low mobility. A compilation of literature data from North America indeed suggests that $\log _{10}$ nestling developmental time does predict $\log _{10}$ fledgling mortality (fig. $2 ; r=-0.87, P<$ .001 ; $\log _{10}$ mass, NS; $n=25$ species; PIC analyses: $P<$ $.001, \mathrm{NS})$. This result is impressive given that these studies include differing habitat types, disturbance levels, and locations (table A2).

Species that fledge after short nestling periods with smaller wings and reduced mobility might simply be more vulnerable to predation than species that fledge with longer wings and greater mobility. In this case, reduced clutch size via reduced reproductive effort may be favored to allow more repeat breeding attempts (see "Evolution of Total Daily Energy Expenditure"). Yet smaller clutch sizes should also be favored if the decrease in fledgling mortality along the fledgling developmental gradient (fig. 2) reflects parental care limitation of the number of fledglings that can be raised.

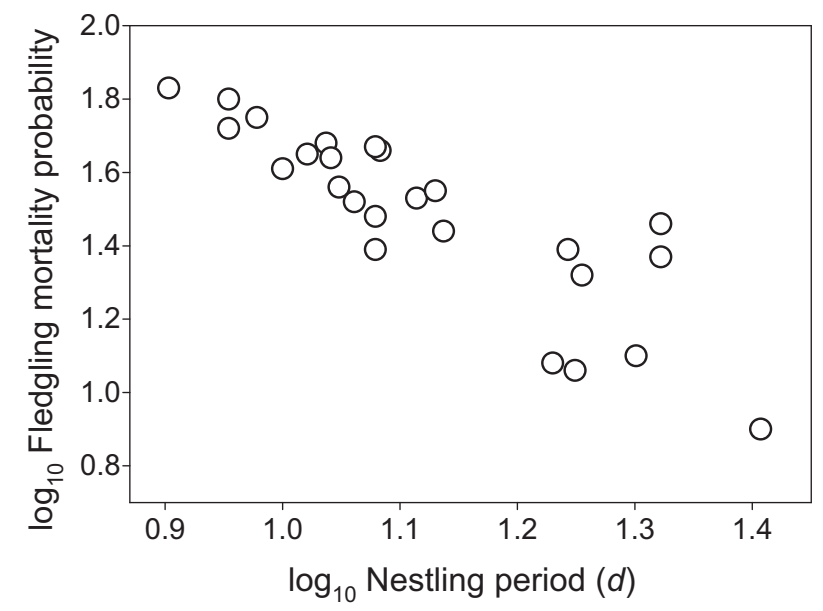

Figure 2: Nestling period ( $\log _{10}$ transformed) predicts fledgling mortality probability ( $\log _{10}$ transformed) over 21 days postfledging among North American songbird (24 species) and woodpecker (1 species) species (data are provided in table A2, available online). 


\section{Partitioning of Parental Energy Expenditure among Offspring}

The fledgling developmental gradient may affect energy requirements per offspring (fig. 1, hypothesis 4: energy requirements per offspring). The better-developed and flight-capable young that emerge after a longer stay in safe nests can more rapidly follow parents as a family group and more rapidly develop self-feeding (Royama 1966; Smith 1967; Brown 1978; With and Balda 1990). These characteristics should reduce travel time and energy costs of parental feeding per offspring. In contrast, the low mobility and reduced development of young that fledge after shorter nestling periods in species with riskier nests require parents to spend significant travel time and energy costs to move between food sources and dispersed fledglings that do not feed themselves (e.g., Sullivan 1989; Kershner et al. 2004; Yackel-Adams et al. 2006; White and Faaborg 2008). Such potential consequences of fledgling characteristics for parental energy expenditure per offspring (fig. 1; hypothesis 4) have never been considered or tested.

To test this hypothesis, I reviewed the literature for studies that measured daily energy expenditure using the doubly labeled water technique during the nestling period (table A1). Parents are injected with ${ }^{18} \mathrm{O}$, which is expired during respiration. Sampling of blood after injection and then a day later allowed estimation of the amount of respiration, or energy expenditure, over this time period (see Weathers and Sullivan 1989; Williams 1996). I used studies during the late nestling period because parents are feeding young at high rates and data were available for the most species at this stage. For this analysis, I assume that parents evolve a relatively fixed level of energy expenditure that does not differ between stages, as supported by existing evidence: studies during incubation and nestling stages across a range of species indicate that daily energy expenditure is similar between the two stages within species (e.g., Williams 1996). Similarly, the only two studies that compared total daily energy expenditure during nestling and fledgling stages also found that energy expenditure remained similar between these two stages (Bryant and Tatner 1988; Weathers and Sullivan 1989). Finally, experimental increases in brood sizes or workload often find that energy expenditure does not increase (e.g., Verhulst and Tinbergen 1997; Wright et al. 1998; Moreno et al. 1999). All of these results suggest that species have evolved a relatively fixed level of parental effort, such that tests with energetic expenditure data from the nestling period are reasonable initial tests of energy expenditure during the fledgling period.

I divided total daily energy expenditure $\left(\mathrm{kJ} \mathrm{day}^{-1}\right)$ by mean clutch size (taken from Martin 1995; Martin and Clobert 1996) to obtain a rough estimate of parental en- ergy expenditure per offspring. The energy requirements per offspring hypothesis (fig. 1, hypothesis 4) predicts that parental energy expenditure per offspring should decrease in species where young remain in the nest longer and fledge at a more advanced stage of development as a result of reduced predation risk. Nestling period is strongly predicted by daily nest predation rates that vary from 0.005 to 0.089 among species on the Arizona site (i.e., Martin et al. 2011) and was strongly correlated with arcsine-trans-
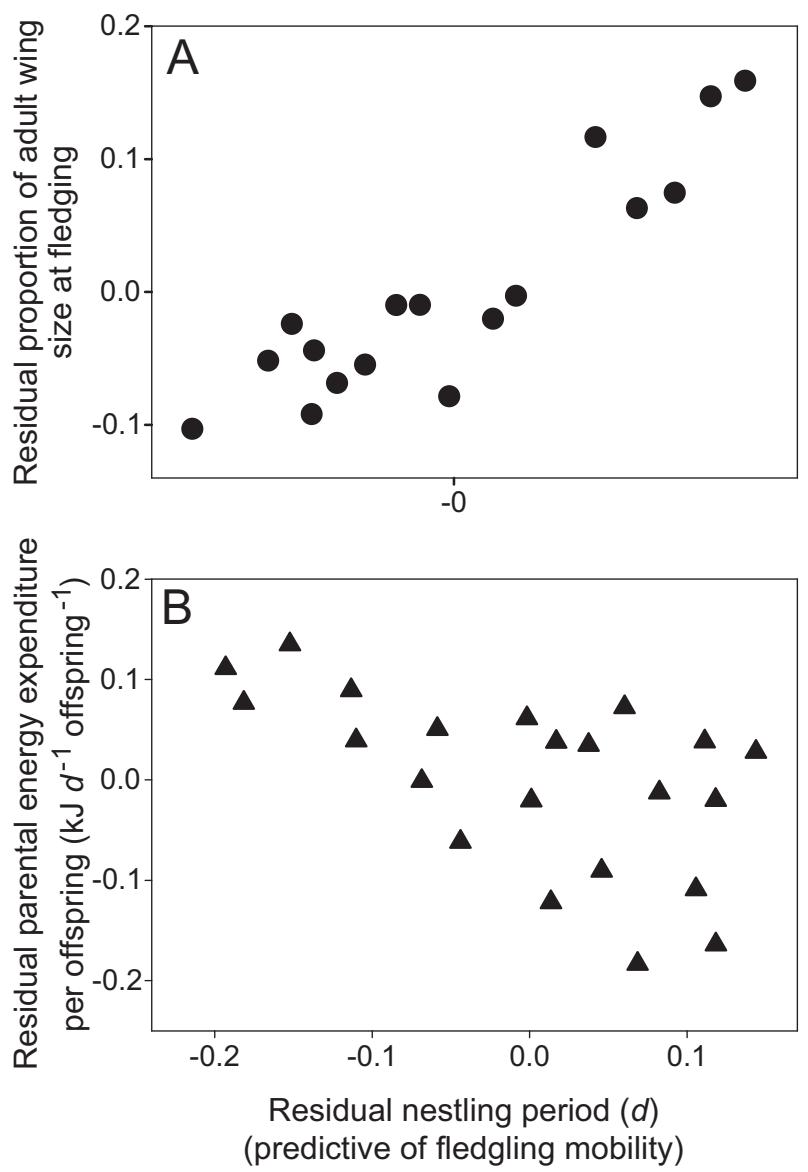

Figure 3: Relative wing chord size and parental energy expenditure per offspring relative to length of the nestling period. A, Relative wing chord size at fledging (proportion of adult wing chord size) is strongly predicted by length of the nestling period, both corrected for body mass and aerial foraging using ordinary linear least squares analysis, and demonstrates that length of the nestling period reflects relative mobility at fledging. Data are for species from the Arizona system (i.e., $n=17$ species; T. E. Martin, unpublished data; Martin et al. 2011; Cheng and Martin 2012). B, Parental daily energy expenditure per offspring (measured using doubly labeled water) is predicted by the nestling period (controlled for mass and aerial foraging) as a predictor of fledgling mobility among north temperate passerine species (data for 22 species from the literature are provided in table A1, available online). Different symbols are used for the different data sets. 
formed proportional wing size at fledging, corrected for body mass (fig. 3A; multiple regression, nestling period: $r_{\mathrm{p}}=0.94, P<.001 ; \log _{10}$ body mass: $r_{\mathrm{p}}=-0.66, P=$ .006; $n=17$ species; PIC analyses: $P<.001, P=.040$, respectively). In short, length of the nestling period is a clear and strong determinant of fledgling developmental state as reflected by wing development at fledging and associated fledgling characteristics such as mobility, spatial dispersion, and development of self-feeding (see "Natural Selection by Nest Predation on Fledgling Developmental Gradient").

Energy expenditure per offspring (log transformed) was negatively related to length of the nestling period (fig. 3B), while controlling for body mass and aerial foraging (GLM, $\log _{10}$ nestling period: $F_{1,18}=-8.5, P=.009 ; \log _{10}$ body mass: $F_{1,18}=236.0, P<.001$; aerial foraging: $F_{1,18}=$ $-30.3, P<.001 ; n=22$ species; PIC analyses: $P=.014$, $P<.001, P<.001$, respectively). Thus, if energy expenditure during the nestling period is similar to that during the fledgling period (see above), then these results show for the first time that energy expenditure per offspring is reduced in species with longer nestling periods (fig. $3 B$ ) that reflect longer relative wing lengths (fig. $3 A$ ), greater mobility, greater spatial clustering, and greater self-feeding (see "Natural Selection by Nest Predation on Fledgling Developmental Gradient").

\section{Evolution of Total Daily Energy Expenditure}

Observed total energetic expenditure has often been interpreted as an ultimate energetic limitation on reproduction in birds (Drent and Daan 1980; Bryant 1997; Welcker et al. 2009, 2010). Yet such arguments have not explained why bird species differ in total energetic expenditure. The fact that species differ in energy expenditure corrected for body mass or basal metabolic rate (e.g., Drent and Daan 1980; Weathers and Sullivan 1989; Williams 1996; Bryant 1997) suggests that energy limitation is not absolute but relative; parents are working at differing evolved levels. This point is emphasized by tropical songbirds, among which offspring number and energy expenditure during nestling feeding are substantially lower than among north temperate species of similar size and ecology (e.g., Bryant et al. 1984; also Steiger et al. 2009).

Differences in total energetic expenditure among species is predicted by classic life-history theory, which suggests that decreased extrinsic adult mortality can favor evolution of decreased reproductive effort (e.g., Williams 1966; Law 1979; Michod 1979; Charlesworth 1994; Roff 2002; fig. 1, hypothesis 5: adult mortality). Indeed, adult mortality probability commonly decreases in the tropics (e.g., Sandercock et al. 2000; Ghalambor and Martin 2001) to potentially favor lower reproductive effort (Martin 2002,
2004). Of course, lower energy expenditure of tropical species may also be facilitated by moderate climate and short days. Yet experiments within species in other taxa show that increases in adult mortality can favor evolution of increased reproductive effort (e.g., Crowl and Covich 1990; Reznick et al. 1990; see Roff 2002). At the same time, total daily energy expenditure for a current breeding attempt may be reduced to save energy for increasing numbers of repeat breeding attempts (fig. 1, hypothesis 6: repeat breeding) associated with increased nest predation risk (fig. 1, hypothesis 7). The increase in repeat breeding, as reflected by numbers of broods, with increasing nest predation risk or season length has already been documented (see Slagsvold 1984; Martin 1995, 2007; Zanette et al. 2006), but the potential effects on energy expenditure have not been tested.

I used the data from the doubly labeled water studies on daily energy expenditure (table A1) together with data on adult mortality and numbers of broods from Martin (1995) and Martin and Clobert (1996) to test the classic adult mortality and repeat breeding hypotheses. Assuming that daily energy expenditure during breeding reflects evolved reproductive effort, then as described above, the hypotheses predict increased parental energy expenditure with increased adult mortality and decreased energy expenditure with increased nest predation. The results show that total daily energy expenditure increased with adult mortality probability (fig. 4A) and simultaneously decreased with numbers of broods (fig. $4 B$ ), while controlling for body mass and aerial foraging (GLM, arcsine adult mortality probability: $F_{1,17}=21.5, P<.001 ; \log _{10}$ numbers of broods: $F_{1,17}=-7.9, P=.012 ; \log _{10}$ body mass: $F_{1,17}=450.2, P<.001$; aerial foraging: $F_{1,17}=-1.1$, $P=.31 ; n=22$ species; PIC analyses: $P<.001, P=$ $.024, P<.001, P=.43$, respectively). Thus, the results show for the first time that differences in evolved levels of parental energy expenditure among species are explained by adult mortality and repeat breeding (fig. 4).

\section{Clutch-Size Evolution}

Energy demand has long been argued to reach its maximum during the fledgling period and limit the number of fledglings (i.e., clutch size) that can be successfully raised (Royama 1966; Edwards 1985; Wolf et al. 1988; Kopachena and Falls 1993; Nesbitt Styrsky et al. 2005). Decreased adult survival with increasing number of fledglings and length of postfledging care in one species (Wheelwright et al. 2003) indicates that the fledgling period can be a period of energy limitation. Yet these studies have not addressed the question of why some species can raise more fledglings than other species and thus why species evolve different clutch sizes. 

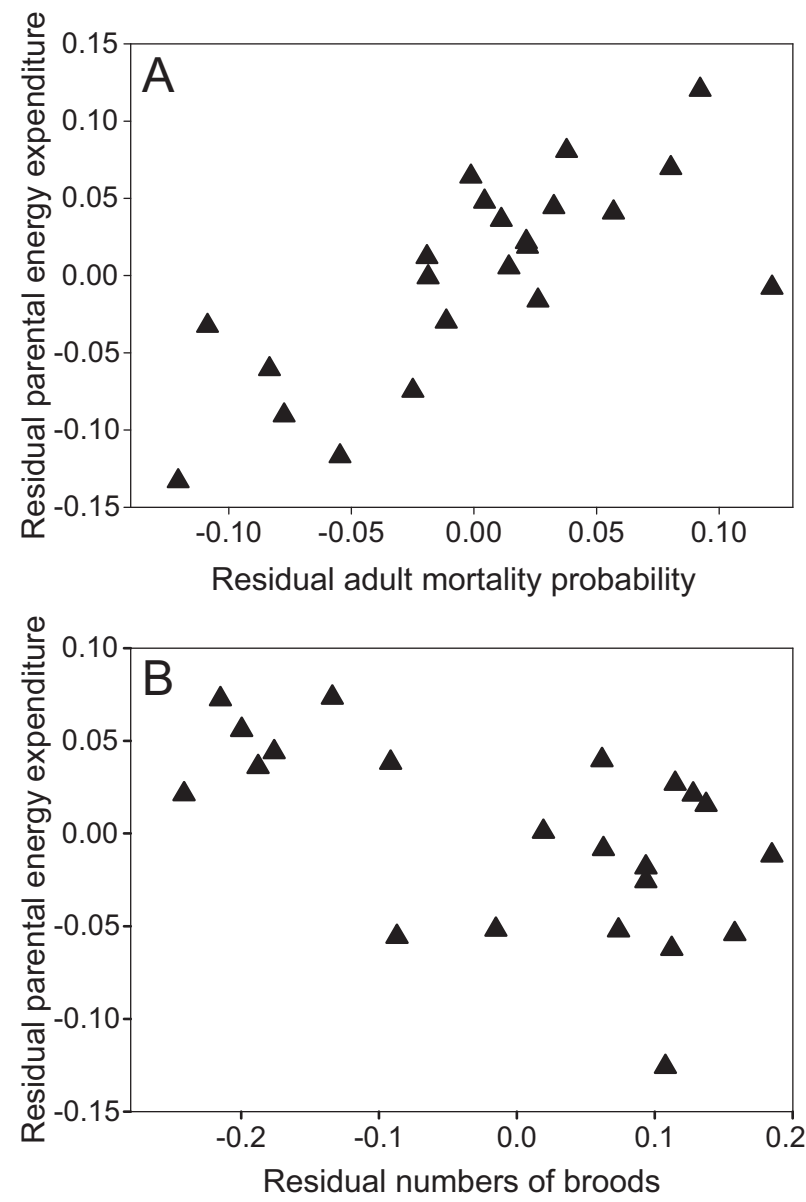

Figure 4: Total daily parental energy expenditure measured using doubly labeled water during brood rearing (i.e., nestling feeding) is predicted by adult mortality probability $(A)$ and numbers of broods per year $(B)$, both corrected for each other plus body mass and aerial foraging using ordinary linear least squares analysis (based on data for 22 species from the literature; table A1, available online). The outlier point at the far end of the adult mortality axis is the European robin (Erithacus rubecula).

A critical aspect of the framework proposed here is that clutch size is not determined simply by evolved total energy expenditure (i.e., reproductive effort). Instead, the gradient in fledgling characteristics is proposed to influence energy requirements per offspring (fig. $3 B$ ) interacting with total energy expenditure (fig. 1, hypothesis 8 : division of evolved reproductive effort) and influence clutch size (fig. 1). In addition, an increase in fledgling mortality with reduced development at fledging (fig. 2) may favor reduced clutch size to allow parents to attempt to reduce mortality risk (fig. 1, hypothesis 9: parental adjustment of fledgling mortality risk). This means that species with similar evolved total energy expenditure may evolve differing clutch sizes because of differences in fledg- ling developmental characteristics and their consequences for energy expenditure per offspring and fledgling mortality.

The potential importance of fledgling developmental characteristics to clutch-size evolution is demonstrated by the Arizona bird species; clutch sizes were strongly explained by relative wing size at fledging (fig. $5 A ; r=0.97$, $P<.001, n=17$ species; PIC analyses: $P<.001$ ), which influences fledgling mobility and is associated with other fledgling developmental characteristics (see "Natural Selection by Nest Predation on Fledgling Developmental Gradient"). Clutch size is often smaller for aerial foragers (Martin 1995), and analyses that corrected for aerial foraging and body size retained the very strong relationship between clutch size and relative wing size at fledging (fig. $5 B$; GLM, arcsine proportional wing size at fledging: $F_{1,13}=427.9, P<.001 ; \log _{10}$ body mass: $F_{1,13}=0.2, P=$ .66 ; aerial foraging: $F_{1,13}=16.3, P=.001$; PIC analyses: $P<.001, P=.85, P=.016$, respectively).

Given that the fledgling developmental gradient is determined by nestling development time (e.g., fig. 3A), I tested the general effects of nestling development time for clutch size across diverse species using the data summarized in Martin (1995) and Martin and Clobert (1996). Clutch size (log transformed) was strongly related to length of the nestling period (fig. 5C) across a diverse group of 180 north temperate passerine species, while controlling for body mass and aerial foraging (GLM, $\log _{10}$ nestling period: $F_{1,176}=66.7, P<.001 ; \log _{10}$ body mass: $F_{1,176}=$ -50.7, $P<.001$; aerial foraging: $F_{1,176}=21.5, P<.001$; PIC analyses: $P<.001, P<.001, P=.001$, respectively). Moreover, if I include adult mortality and numbers of broods to account for evolved total energy expenditure (i.e., fig. 4), length of the nestling period still explains variation in clutch size (GLM, $\log _{10}$ nestling period: $F_{1,134}=25.1, P<.001$; arcsine adult mortality probability: $F_{1,134}=76.2, P<.001 ; \log _{10}$ numbers of broods: $F_{1,134}=$ $-41.1, P<.001$; $\log _{10}$ body mass: $F_{1,134}=-4.1, P=$ .044; aerial foraging: $F_{1,134}=51.0, P<.001$; PIC analyses: $P=.001, P<.001, P<.001, P=.54, P<.001$, respectively). These results, in both the Arizona system and more generally across north temperate passerine species, support the prediction that clutch size is larger in species where nestlings stay longer in nests (fig. 5) to yield fledglings with longer relative wing size (fig. $3 A$ ), greater fledgling mobility, fledglings moving in groups, and faster development of self-feeding (see references cited in "Natural Selection by Nest Predation on Fledgling Developmental Gradient").

Ultimately, the energy demands and mortality consequences of fledgling characteristics should interact with evolved total parental energy expenditure to determine clutch size, as supported by the analysis above. I tested 

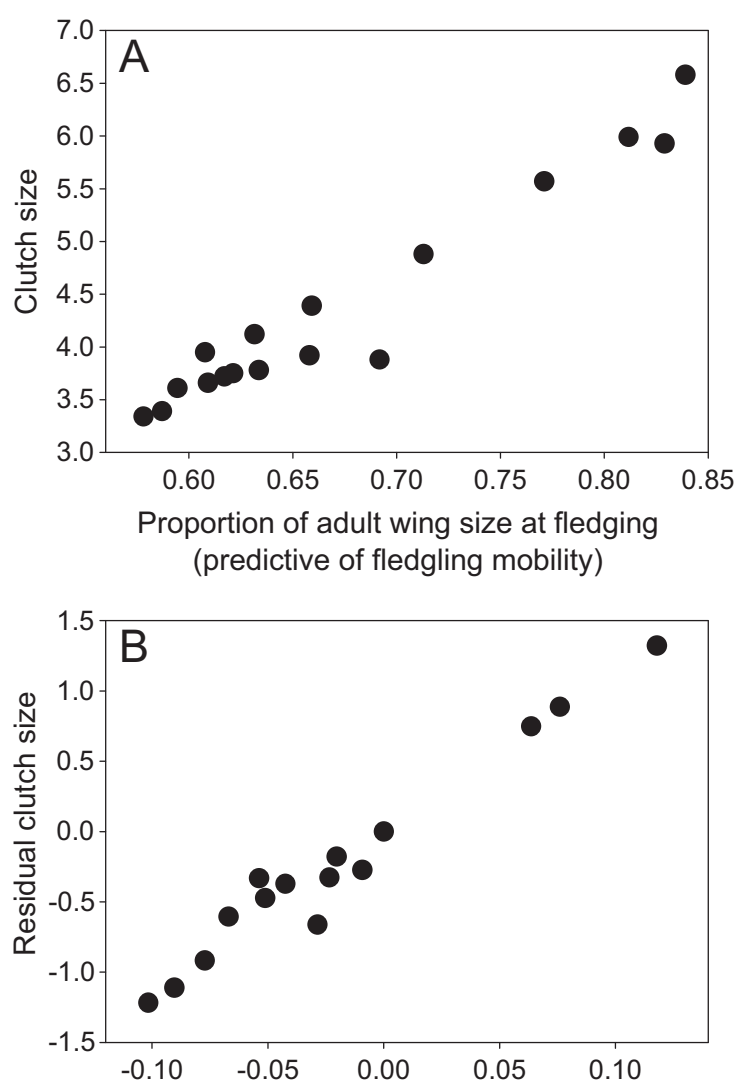

Residual proportion of adult wing size at fledging (predictive of fledgling mobility)

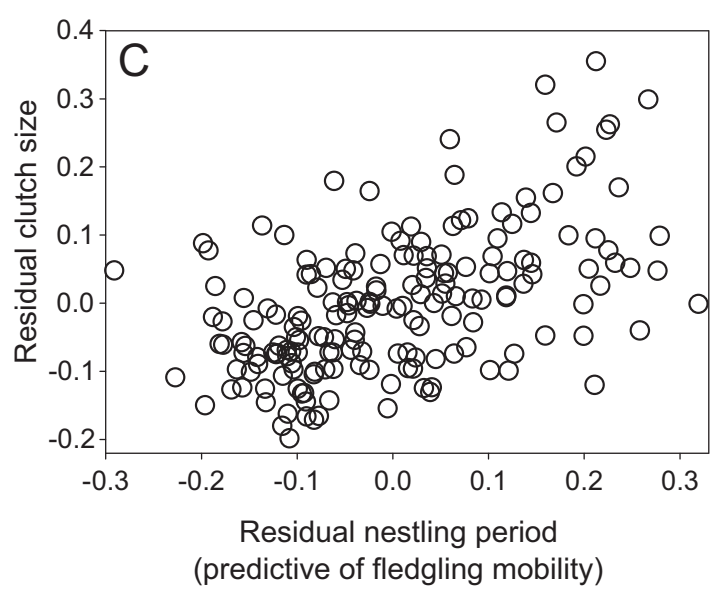

Figure 5: Clutch size is predicted by relative wing chord size at fledging as a proportion of adult wing chord size across passerine species in the Arizona system based on raw data $(n=16$ species; $A$ ) and when corrected for body mass and aerial foraging using ordinary linear least squares analysis $(n=17$ species; $B)$. $C$, Clutch size is also predicted more generally by length of the nestling period as a determinant of fledgling mobility (i.e., fig. $3 A$ ), corrected for body mass and aerial foraging using ordinary linear least squares analysis ( $n=180$ north temperate passerines from Martin [1995] and Martin and Clobert [1996]). this further using the literature data on parental energy expenditure (table A1) and nestling period as the determinant of fledgling characteristics. Clutch size (log transformed) was indeed predicted by both total daily energy expenditure and fledgling development as reflected by length of the nestling period, while controlling for body mass and aerial foraging (fig. $6 \mathrm{~A}, 6 \mathrm{~B}$; $\log _{10}$ total daily energy expenditure: $F_{1,17}=13.5, P=.002$; $\log _{10}$ nestling period: $F_{1,17}=8.2, P=.011$; $\log _{10}$ body mass: $F_{1,17}=18.6, P<$ .001 ; aerial foraging: $F_{1,17}=21.9, P<.001$; PIC analyses: $P=.003, P=.008, P=.001, P<.001$, respectively). The relationship between clutch size and energy expenditure (fig. $6 \mathrm{~A}$ ) is made stronger by the outlier to the farleft lower corner (Auriparus flaviceps) but is made weaker by the next-most left species (Progne subis), which has a very long nestling period ( 28 days, the rightmost outlier in fig. 6B). If these two outliers are removed, log-transformed clutch size remains predicted by total daily energy expenditure and fledgling developmental state as determined by length of the nestling period (fig. 6C, 6D; GLM, $\log _{10}$ total daily energy expenditure: $F_{1,15}=7.0, P=.019$; $\log _{10}$ nestling period: $F_{1,15}=12.0, P=.003 ; \log _{10}$ body mass: $F_{1,15}=16.1, P=.001$; aerial foraging: $F_{1,15}=39.3$, $P<.001$; PIC analyses: $P=.046 ; P=.002 ; P=.004$; $P<.001$, respectively). Variation in reproductive effort (total daily energy expenditure) has long been argued to be the primary limit on fecundity, or clutch size (Williams 1966; Drent and Daan 1980; Bryant 1997). Yet the results here suggest that the developmental state of offspring and the consequences for energy requirements and mortality influence how total daily energy expenditure is allocated among young.

\section{Discussion}

Classic life-history theory, based on age-specific mortality (e.g., Williams 1966; Law 1979; Michod 1979; Charlesworth 1994), appears to explain evolution of reproductive effort as reflected by total daily energy expenditure (fig. 4; see "Energy Expenditure" below). Yet this theory explains how much energy is allocated to reproduction but not how it is apportioned among offspring to explain differences in clutch size among species with similar reproductive effort. The evidence provided here, while correlative and sometimes indirect, indicates that nest predation exerts selection on nestling development time to thereby affect fledgling characteristics, which in turn influence apportionment of energy among offspring (fig. $3 B$ ). Variation among species in fledgling characteristics and the potential consequences for differential mortality and energy expenditure per offspring have not been considered previously in theories of clutch-size evolution among species. Yet differences in mobility, spatial dispersion, and self-feeding 

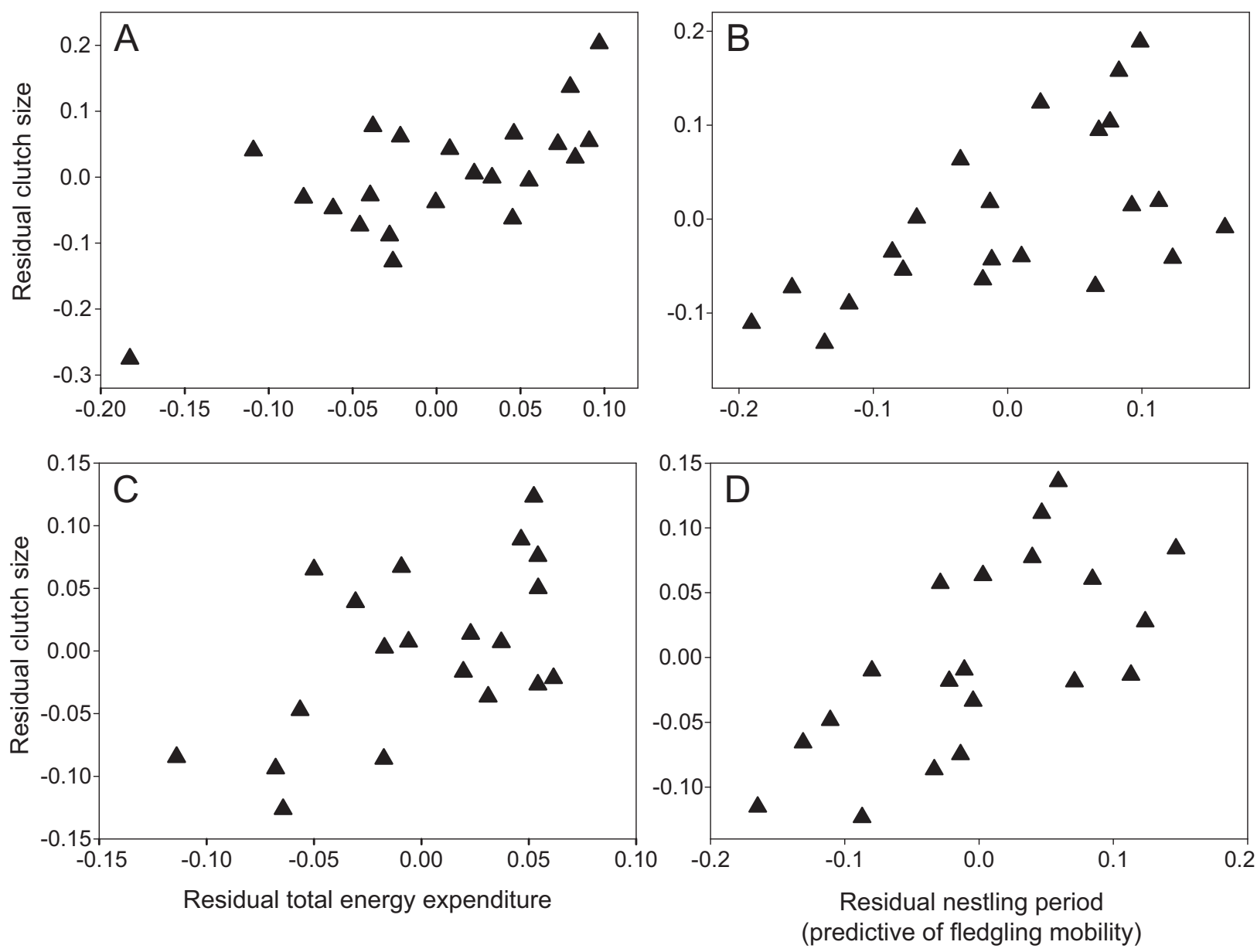

Figure 6: Clutch size is predicted by total daily parental energy expenditure $(A)$ and length of the nestling period $(B)$ as a determinant of fledgling mobility (see fig. $3 A$ ), while controlled for each other plus mass and aerial foraging using ordinary linear least squares analysis (based on data for 22 species from the literature; table A1, available online). If the two left-most species (Auriparus flaviceps farthest left, followed by Progne subis) in the energy expenditure cell $(A)$ are removed, clutch size remains predicted by parental energy expenditure $(C)$ and length of the nestling period $(D)$ as an index of fledgling mobility $(n=20$ species).

appear to yield large differences in fledgling mortality and energy costs per offspring to the parents (e.g., figs. 2, 3B). These should influence the number of offspring that parents attempt to raise (fig. 1). The strong relationships of clutch size with fledgling developmental state, even after accounting for total reproductive effort (figs. 5, 6), certainly suggest an important role for fledgling developmental characteristics in clutch-size evolution.

\section{Energy Expenditure}

The theory presented here does not depend on energy being most limiting in the fledgling stage. The theory proposes that variation in fledgling mortality and energy required per offspring due to fledgling developmental characteristics (i.e., figs. 2, 3B) can cause differential parti- tioning of evolved total daily energy expenditures to influence clutch size (figs. 5, 6). In other words, two species with the same total energy expenditure may evolve differing clutch sizes due to these consequences of differing developmental states at fledging on energy and mortality.

Of course, variation among species in evolved levels of total energy expenditure (fig. 4) should also contribute to clutch-size variation (fig. 1). Total daily energy expenditure varies little over nesting stages, brood sizes, time, and food availability (e.g., Verhulst and Tinbergen 1997; Wright et al. 1998; Moreno et al. 1999; Welcker et al. 2009, 2010), suggesting a relatively fixed evolved level within species. Yet correction for body mass shows that species differ in their relative levels of energy expenditure, or reproductive effort (fig. 4). Classic life-history theory and experimental tests in taxa other than birds suggest that increased adult 
mortality favors increased reproductive effort, while increased juvenile mortality favors reduced effort (Williams 1966; Law 1979; Michod 1979; Crowl and Covich 1990; Reznick et al. 1990; Charlesworth 1994). The framework proposed here suggests that this theory may apply across species of songbirds: adult mortality favors increased reproductive effort, and repeated nesting attempts associated with greater nest predation risk favors reduced effort per nesting attempt (fig. 4). These evolved differences in relative total energy expenditure (reproductive effort) explain some of the variation in clutch size (fig. 6), as expected by traditional theory.

Yet the mortality (fig. 2) and per-offspring energy (fig. $3 B$ ) consequences of fledgling developmental characteristics are proposed to underlie differential partitioning of reproductive effort among offspring. This latter aspect provides a potential mechanistic explanation for why species with similar total effort might evolve different clutch sizes. The fact that developmental state at fledging, as reflected by the length of the nestling development period, explains substantial amounts of clutch-size variation even after accounting for reproductive effort (i.e., fig. 6) supports the postulation that fledgling characteristics, as influenced by nest predation risk, are a critical determinant of clutchsize evolution. Ultimately, the framework proposed here marries classic life-history theory on evolution of reproductive effort to new hypotheses on fledgling developmental state for apportionment of energy among young to determine clutch size.

\section{Fledgling Mortality and Adaptive Age at Fledging}

Offspring of species that leave the nest at a young age with relatively less-developed wings appear to do so because of high nest predation risk (Cheng and Martin 2012). Fledging at younger ages may reduce risk of predation in the nest, but the reduced mobility also increases mortality after leaving the nest as fledglings (fig. 2). Yet early age at fledging can be adaptive, even with high postfledging mortality, if risk of mortality to fledglings is less than or similar to that to nestlings (Roff et al. 2005). Such effects are not clear (McLaughlin and Montgomerie 1989b), but several studies have found similar or higher daily survival rates during fledgling compared with nestling stages (e.g., Anders et al. 1997; Yackel-Adams et al. 2006; Moore et al. 2010). Thus, the high mortality from early fledging in high risk nests is potentially adaptive, although rigorous tests of this hypothesis are needed. Ultimately, differential mortality from parental care limitations and vulnerability to predation as a function of mobility among species should constrain clutch size. Comparative brood reduction experiments that track fledgling survival for species that con- trast in fledgling developmental state could ascertain relative limits imposed by parental care.

\section{Density Dependence}

One possible outcome of differential mortality of fledglings as a function of nest safety and developmental state (i.e., fig. 2) may be differential consequences for densitydependent mortality. Cavity-nesting species have large clutch sizes with high nest success (Lack 1948; Martin 1995) and low fledgling mortality because of greater development (fig. 2), such that resulting high postbreeding densities might yield strong density-dependent mortality over the lean season. In contrast, open-nesting species with smaller clutch sizes, lower nest success, and higher fledgling mortality may suffer little density-dependent mortality. Such differences in density dependence across species have not been proposed but deserve study. Indeed, this proposition is opposite to historical arguments that species with slow (i.e., K-selected) life histories are under greater density-dependent selection than those with fast life histories (Skutch 1949, 1967; MacArthur and Wilson 1967; Murphy 1968; Pianka 1970).

\section{Conclusions}

Ultimately, the framework presented here (fig. 1) incorporates elements of traditional life-history theory on evolution of reproductive effort with new mechanistic elements based on differential consequences of developmental differences for apportioning that effort among young. This framework suggests that age-specific mortality may form the primary source of environmental selection that yields the mechanistic interactions (fig. 1). Yet this mortality selection acts both on evolution of reproductive effort and on developmental strategies that may influence apportioning of energy among young. While support is correlative and indirect in some cases, documented relationships (figs. 2, 3, 5, 6) were previously unrecognized and provide abundant opportunities for experimental tests. Studies of these proposed hypotheses could advance theories of clutch-size evolution, energy expenditure and limitation, development strategies, adaptive age at fledging, and density dependence.

\section{Acknowledgments}

I am grateful to K. P. Dial for helpful discussions and to R. J. Fletcher, J. LaManna, J. C. Oteyza, S. Sillett, R. Ton, and two anonymous reviewers for helpful comments on the manuscript. I thank W. A. Cox for sharing independent discovery of a relationship between nestling period and 
fledgling mortality and for providing additional comments. This work was supported by the National Science Foundation (grants DEB-0841764 and DEB-1241041) ana the US Geological Survey Climate Change Research Program. Work in Arizona was conducted under University of Montana Institutional Animal Care and Use Committee (IACUC) protocol 059-10TMMCWRU. Any use of trade names is for descriptive purposes only and does not imply endorsement by the US government. survival of Eastern Bluebirds in an urbanized landscape. Journal of Wildlife Management 75:1082-1093.

Jetz, W., C. H. Sekercioglu, and K. Böhning-Gaese. 2008. The worldwide variation in avian clutch size across species and space. PLoS Biology 6:e303.

Jetz, W., G. H. Thomas, J. B. Joy, K. Hartmann, and A. O. Mooers. 2012. The global diversity of birds in space and time. Nature 491: 444-448.

$\rightarrow$ Kershner, E. L., J. W. Walk, and R. E. Warner. 2004. Postfledging movements and survival of juvenile eastern meadowlarks (Sturnella magna) in Illinois. Auk 121:1146-1154.

$\rightarrow$ King, D. I., R. M. Degraaf, M. L. Smith, and J. P. Buonaccorsi. 2006. Habitat selection and habitat-specific survival of fledgling ovenbirds (Seiurus aurocapilla). Journal of Zoology 269:414-421.

\section{Literature Cited}

$\rightarrow$ Kopachena, J. G., and J. B. Falls. 1993. Postfledging parental care in the white-throated sparrow (Zonotrichia albicollis). Canadian Journal of Zoology 71:227-232.

Anders, A. D., D. C. Dearborn, J. Faaborg, and F. R. Thompson III. 1997. Juvenile survival in a population of Neotropical migran ${ }^{2}$ birds. Conservation Biology 11:698-707.

$\rightarrow$ Anthonisen K., C. Krokene, and J. T. Lifjeld. 1997. Brood divisior is associated with fledgling dispersion in the bluethroat (Luscinia s. svecica). Auk 114:553-561.

Ashmole, N. P. 1961. The biology of certain terns: with special reference to the black noddy (Anous tenuirostris) and the wideawake tern (Sterna fuscata) on Ascension Island, England. $\mathrm{PhD}$ thesis. Oxford University, Oxford.

$\rightarrow$ Bosque, C., and M. T. Bosque. 1995. Nest predation as a selective factor in the evolution of developmental rates in altricial birds. American Naturalist 145:234-260.

$\rightarrow$ Brown, C. R. 1978. Post-fledging behavior of Purple Martins. Wilson Bulletin 90:376-385.

$\rightarrow$ Bryant D. M. 1997. Energy expenditure in wild birds. Proceedings of the Nutrition Society 56:1025-1039.

$\rightarrow$ Bryant, D. M., C. J. Hails, and P. Tatner. 1984. Reproductive energetics of two tropical bird species. Auk 101:25-37.

$\rightarrow$ Bryant, D. M., and P. Tatner. 1988. Energetics of the annual cycle of dippers Cinclus cinclus. Ibis 130:17-38.

Charlesworth, B. 1994. Evolution in age-structured populations. Cambridge University Press, Cambridge.

$\rightarrow$ Cheng, Y., and T. E. Martin. 2012. Nest predation risk and growth strategies of passerine species: grow fast or develop traits to escape risk? American Naturalist 180:285-295.

$\rightarrow$ Crowl, T. A., and A. P. Covich. 1990. Predator-induced life-history shifts in a freshwater snail. Science 247:949-951.

Drent, R. H., and S. Daan. 1980. The prudent parent: energetic $\rightarrow$ adjustments in avian breeding. Ardea 68:225-252.

$\rightarrow$ Edwards, P. J. 1985. Brood division and transition to independence in Blackbirds Turdus merula. Ibis 127:42-59.

$\rightarrow$ Evans Ogden, L. J., and B. J. M. Stutchbury. 1997. Fledgling care anc $\rightarrow$ male parental effort in the Hooded Warbler (Wilsonia citrina). Canadian Journal of Zoology 75:576-581.

$\rightarrow$ Felsenstein, J. 1985. Phylogenies and the comparative method. Amer ican Naturalist 125:1-15.

$\rightarrow$ Ghalambor, C. K., and T. E. Martin. 2001. Fecundity-survival tradeoffs and parental risk-taking in birds. Science 292:494-497.

$\rightarrow$ Godfray, H. C. J., L. Partridge, and P. H. Harvey. 1991. Clutch size. Annual Review of Ecology and Systematics 22:409-429.

$\rightarrow$ Hackett, S. J., R. T. Kimball, S. Reddy, R. C. K. Bowie, E. L. Braun, M. J. Braun, J. L. Chojnowski, et al. 2008. A phylogenomic study of birds reveals their evolutionary history. Science 320:1763-1768

$\rightarrow$ Jackson, A. K., J. P. Froneberger, and D. A. Cristol. 2011. Postfledging
Lack, D. 1948. The significance of clutch size. Part 3. Some interspecific comparisons. Ibis 90:25-45.

Law, R. 1979. Optimal life histories under age-specific predation. American Naturalist 114:399-417.

MacArthur, R. H., and E. O. Wilson. 1967. Theory of island biogeography. Princeton University Press, Princeton, NJ.

Maddison, W. P., and D. R. Maddison. 2011. Mesquite: a modular system for evolutionary analysis. Version 2.75. http:// mesquiteproject.org.

Magrath, R. D. 1991. Nestling weight and juvenile survival in the blackbird, Turdus merula. Journal of Animal Ecology 60:335-351.

$\rightarrow$ Martin, T. E. 1987. Food as a limit on breeding birds: a life-history perspective. Annual Review of Ecology and Systematics 18:453487.

- 1995. Avian life history evolution in relation to nest sites, nest predation and food. Ecological Monographs 65:101-127.

2002. A new view for avian life history evolution tested on an incubation paradox. Proceedings of the Royal Society B: Biological Sciences 269:309-316.

$\rightarrow \longrightarrow$. 2004. Avian life-history evolution has an eminent past: does it have a bright future? Auk 121:289-301.

2007. Climate correlates of 20 years of trophic changes in a high elevation riparian system. Ecology 88:367-380.

- 2014. Data from: A conceptual framework for clutch-size evolution in songbirds. American Naturalist, Dryad Digital Repository, http://dx.doi.org/10.5061/dryad.8415f.

Martin, T. E., R. D. Bassar, S. K. Bassar, J. J. Fontaine, P. Lloyd, H. Mathewson, A. Niklison, and A. Chalfoun. 2006. Life history and ecological correlates of geographic variation in egg and clutch mass among passerine species. Evolution 60:390-398.

$\rightarrow$ Martin, T. E., and J. Clobert. 1996. Nest predation and avian life history evolution in Europe versus North America: a possible role of humans? American Naturalist 147:1028-1046.

$\rightarrow$ Martin, T. E., P. Lloyd, C. Bosque, D. Barton, L. Biancucci, Y. Cheng, and R. Ton. 2011. Growth rate variation among passerine species in temperate and tropical sites: an antagonistic interaction between parental food provisioning and nest predation risk. Evolution 65: $1607-1622$.

$\rightarrow$ Martin, T. E., P. R. Martin, C. R. Olson, B. J. Heidinger, and J. J. Fontaine. 2000. Parental care and clutch sizes in North and South American birds. Science 287:1482-1485.

McLaughlin, R. L., and R. D. Montgomerie. 1985. Brood division by Lapland longspurs. Auk 102:687-695. 
$\rightarrow-$. 1989a. Brood dispersal and multiple central place foragin by Lapland longspur parents. Behavioral Ecology and Sociobiology 25:207-215.

$\rightarrow-1989 b$. Early nest departure does not improve the survival of Lapland longspur chicks. Auk 106:738-741.

$\rightarrow$ Michod, R. E. 1979. Evolution of life histories in response to agespecific mortality factors. American Naturalist 113:531-550.

Midford, P. E., T. Garland Jr., and W. Maddison. 2002. PDAP:PDTree package for Mesquite, version 1.00. http://mesquiteproject.org /pdap_mesquite/.

$\rightarrow$ Moore, L. C., B. J. Stutchbury, D. M. Burke, and K. A. Elliott. 2010 Effects of forest management on postfledging survival of Rosebreasted Grosbeaks (Pheucticus ludovicianus). Auk 127:185-194.

$\rightarrow$ Moreno, J., S. Merino, J. Potti, A. De Leon, and R. Rodríguez. 1999. $\rightarrow$ Maternal energy expenditure does not change with flight costs or food availability in the pied flycatcher (Ficedula hypoleuca): costs and benefits for nestlings. Behavioral Ecology and Sociobiology 46:244-251.

$\rightarrow$ Murphy, G. I. 1968. Pattern in life history and the environment. American Naturalist 102:390-404.

$\rightarrow$ Nesbitt Styrsky, J., J. D. Brawn, and S. K. Robinson. 2005. Juvenile mortality increases with clutch size in a Neotropical bird. Ecology 86:3238-3244.

$\rightarrow$ Pianka, E. R. 1970. On $r$ - and K-selection. American Naturalist 104: 592-597.

$\rightarrow$ Raihani, N. J., and A. R. Ridley. 2007. Adult vocalizations during provisioning: offspring response and postfledging benefits in wild pied babblers. Animal Behavior 74:1303-1309.

$\rightarrow$ Remeš, V., and T. E. Martin. 2002. Environmental influences on the evolution of growth and developmental rates in passerines. Evolution 56:2505-2518.

$\rightarrow$ Reznick, D. A., H. Bryga, and J. A. Endler. 1990. Experimentally induced life-history evolution in a natural population. Nature 346: 357-359.

$\rightarrow$ Ricklefs, R. E. 2010. Parental investment and avian reproductive rateWilliam's principle reconsidered. American Naturalist 175:350361 .

Roff, D. A. 2002. Life history evolution. Sinauer, Sunderland, MA.

Roff, D. A., V. Remeš, and T. E. Martin. 2005. The evolution of fledging age in songbirds. Journal of Evolutionary Ecology 18: 1425-1433.

$\rightarrow$ Royama, T. R. 1966. Factors governing feeding rate, food requirement and brood size of nestling Great Tits Parus major. Ibis 108:313347.

$\rightarrow$ Rush, S. A., and B. J. Stutchbury. 2008. Survival of fledgling Hooded Warblers (Wilsonia citrina) in small and large forest fragments. Auk 125:183-191.

$\rightarrow$ Sandercock, B. K., S. R. Beissinger, S. H. Stoleson, R. R. Melland and C. R. Hughes. 2000. Survival rates of a Neotropical parrot: implications for latitudinal comparisons of avian demography. Ecology 81:1351-1370.

$\rightarrow$ Skutch, A. F. 1949. Do tropical birds rear as many young as they can nourish? Ibis 91:430-455.

$\rightarrow-$. 1967. Adaptive limitation of the reproductive rate of birds Ibis 109:579-599.

$\rightarrow$ Slagsvold, T. 1984. Clutch size variation of birds in relation to nest predation: on the cost of reproduction. Journal of Animal Ecology 53:945-953.
Smith, S. M. 1967. Seasonal changes in the survival of the Blackcapped Chickadee. Condor 69:344-359.

$\rightarrow$ Steiger, S. S., J. P. Kelley, W. W. Cochran, and M. Wikelski. 2009. Low metabolism and inactive lifestyle of a tropical rain forest bird investigated via heart-rate telemetry. Physiological and Biochemical Zoology 82:580-589.

Streby, H. M., and D. E. Andersen. 2013. Movements, cover-type selection, and survival of fledgling Ovenbirds in managed deciduous and mixed coniferous-deciduous forests. Forest Ecology and Management 287:9-16.

Suedkamp Wells, K. M., M. R. Ryan, J. J. Millspaugh, F. R. Thompson III, and M. W. Hubbard. 2007. Survival of postfledging grassland birds in Missouri. Condor 109:781-794.

Sullivan, K. A. 1989. Predation and starvation: age-specific mortality in juvenile juncos (Junco phaenotus). Journal of Animal Ecology 58:275-286.

Verhulst, S., and J. M. Tinbergen. 1997. Clutch size and parental effort in the Great Tit Parus major. Ardea 85:111-126.

Weathers, W. W., and K. A. Sullivan. 1989. Juvenile foraging proficiency, parental effort, and avian reproductive success. Ecological Monographs 59:223-246.

Welcker, J., A. Harding, A. S. Kitaysky, J. R. Speakman, and G. W. Gabrielsen. 2009. Daily energy expenditure increases in response to low nutritional stress in an Arctic-breeding seabird with no effect on mortality. Functional Ecology 23:1081-1090.

Welcker, J., B. Moe, C. Bech, M. Fyhn, J. Schultner, J. R. Speakman, and G. W. Gabrielsen. 2010. Evidence for an intrinsic energetic ceiling in free-ranging kittiwakes Rissa tridactyla. Journal of Animal Ecology 79:205-213.

Wheelwright, N. T., K. A. Tice, and C. R. Freeman-Gallant. 2003. Postfledging parental care in Savannah sparrows: sex, size and survival. Animal Behavior 65:435-443.

White, J. D., and J. Faaborg. 2008. Post-fledging movement and spatial habitat-use patterns of juvenile Swainson's thrushes. Wilson Bulletin 120:62-73.

Williams, G. C. 1966. Natural selection, the costs of reproduction, and a refinement of Lack's principle. American Naturalist 100: 687-690.

Williams, J. B. 1996. Energetics of avian incubation. Pages 375-416 in C. Carey, ed. Avian energetics and nutritional ecology. Chapman and Hall, New York.

$\rightarrow$ With, K. A., and R. P. Balda. 1990. Intersexual variation and factors affecting parental care in Western Bluebirds: a comparison of nestling and fledgling periods. Canadian Journal of Zoology 68:733742.

$\rightarrow$ Wolf, L., E. D. Ketterson, and V. Nolan. 1988. Paternal influence on growth and survival of dark-eyed junco young: do parental males benefit? Animal Behavior 36:1601-1618.

Wright, J., C. Both, P. A. Cotton, and D. Bryant. 1998. Quality vs. quantity: energetic and nutritional trade-offs in parental provisioning strategies. Journal of Animal Ecology 67:620-634.

$\rightarrow$ Yackel-Adams, A. A., S. K. Skagen, and J. A. Savidge. 2006. Modeling post-fledging survival of Lark Buntings in response to ecological and biological factors. Ecology 87:178-188.

Zanette, L., M. Clinchy, and J. N. M. Smith. 2006. Food and predators affect egg production in song sparrows. Ecology 87:2459-2467.

Associate Editor: Carlos Martínez del Rio Editor: Judith L. Bronstein 